\title{
A Multifrequency Radiometer System
}

\section{Skou, Niels}

Published in:

Microwave Conference, 1977. 7th European

Link to article, DOI:

10.1109/EUMA.1977.332460

Publication date:

1977

\section{Document Version}

Publisher's PDF, also known as Version of record

Link back to DTU Orbit

Citation (APA):

Skou, N. (1977). A Multifrequency Radiometer System. In Microwave Conference, 1977. 7th European (pp. 419423). IEEE. https://doi.org/10.1109/EUMA.1977.332460

\section{General rights}

Copyright and moral rights for the publications made accessible in the public portal are retained by the authors and/or other copyright owners and it is a condition of accessing publications that users recognise and abide by the legal requirements associated with these rights.

- Users may download and print one copy of any publication from the public portal for the purpose of private study or research.

- You may not further distribute the material or use it for any profit-making activity or commercial gain

- You may freely distribute the URL identifying the publication in the public portal

If you believe that this document breaches copyright please contact us providing details, and we will remove access to the work immediately and investigate your claim 
Niels Skou*

\section{ABSTRACT}

A radiometer system having four channels: $5 \mathrm{GHz}, 17 \mathrm{GHz}, 34 \mathrm{GHz}$, all vertical polarization, and a $34 \mathrm{GHz}$ sky horn, will be described.

The system which is designed for collecting glaciological and oceanographic data is intended for airborne use and imaging is achieved by means of a multifrequency conically scanning antenna.

Implementation of the noise-injection technique ensures the high absolute accuracy needed for oceanographic purposes.

The collected data can be preprocessed in a microcomputer system and displayed in real time. Simultaneously, the data are recorded digitally on tape for more elaborate processing later, using ground facilities.

In conjunction with a side looking radar which is under development at present, the radiometers are intended as the remote sensing basis for an all-weather ice reconnaissance service in the Greenland seas.

\section{INTRODUCTION}

The sea ice in Greenland waters consists of multi-year and first-year ice as well as new ice recently formed. Scientifically and practically, it is of importance to be able to distinguish between these ice categories. Experience has shown that this may be done by simultaneous measurements with a set of radiometers at different frequencies [1].

The radiometer system described in this paper implies 3 frequencies: 5, 17 and $34 \mathrm{GHz}$. The system however, comprises 4 channels, the main antenna and a sky horn sharing the $34 \mathrm{GHz}$ radiometers by multiplexing.

Sea ice reconnaissance implies coverage of large areas within limited time, calling for an airborne system including a scanning antenna.

Table I shows typical measuring conditions:

Table I: Flight altitude Aircraft velocity Antenna aperture Angle-of-incidence Scan angle Swath width Polarization

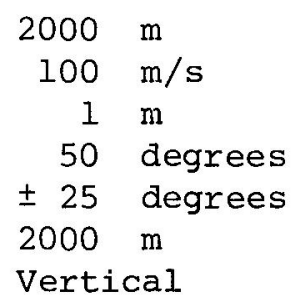

The scanning of the antenna makes the footprint dwell time, hence the

* Electromagnetics Institute Technical University of Denmark 2800-Lyngby, Denmark 
radiometer integration time, very short, calling for careful design to ensure reasonable sensitivities.

\section{DESCRIPTION OF THE RADIOMETERS}

The main parameters and the performances, regarding the measurement conditions stated in Table I, are shown in Table II:

Table II

Frequencies

Input bandwidths

Foot print size

Foot prints per swath

Dwell time per foot print

Radiometer constant

Sensitivity

$$
5 \mathrm{GHz}
$$

500. MHz

$300 \times 470 \mathrm{~m}$

7

0.7 sec

$0.085^{\circ} \mathrm{K}$

$0.18^{\circ} \mathrm{K}$
$17 \mathrm{GHz}$

$1 \mathrm{GHz}$

$88 \times 138 \mathrm{~m}$

23

$60 \mathrm{msec}$

$0.085^{\circ} \mathrm{K}$

$0.06^{\circ} \mathrm{K}$
$34 \mathrm{GHz}$

$1 \mathrm{GHz}$

$44 \times 68 \mathrm{~m}$

45

$15 \mathrm{msec}$

$0.085^{\circ} \mathrm{K}$

$1.2^{\circ} \mathrm{K}$

All three radiometers are essentially identical and operate according to the noise-injection principle. By this principle, noise from a semiconductor diode is added to the noise from the antenna to give a constant output of the radiometer. Thus, the antenna temperature, which is the parameter to be determined as a measure of the noise temperatures within the field of view of the antenna, is measured indirectly by the amount of internally generated noise. Since the noise power in the system is kept constant and equal to that from a reference load, it can be shown that a greater measurement accuracy can be obtained, compared with conventional radiometers, provided all microwave components are kept at a constant temperature equal to that of the reference load $[2]$.

The principle of the radiometers is shown in Fig. I. In addition to the components normally found in Dicke radiometers, this diagram is characterized by the noise injection circuitry - controlled by the $A / D$ converter.

The $A / D$ converter is a "voltage to pulse-rate" converter and thus the injected noise is of constant amplitude but variable duty-cycle. The number of pulses from the $A / D$ converter counted in fixed consecutive time periods is directly a measure of the injected noise, hence the antenna temperature.

All components within the dotted line in Fig. 1 (see Fig. 2) are placed in a temperature stabilized box $\left(40^{\circ} \mathrm{C}\right)$ and the temperature of critical parts is electronically monitored. Also, temperatures of the antenna assembly are monitored. In total, 16 temperature measurements are performed to be used to correct the radiometer data.

An absolute accuracy of less than $0.50 \mathrm{~K}$ is achieved by the described technique.

The radiometer data and the temperature measurement data are formatted and recorded on magnetic tape. The formatter also accepts navigational 
data from the inertial navigation system of the aeroplane for recording.

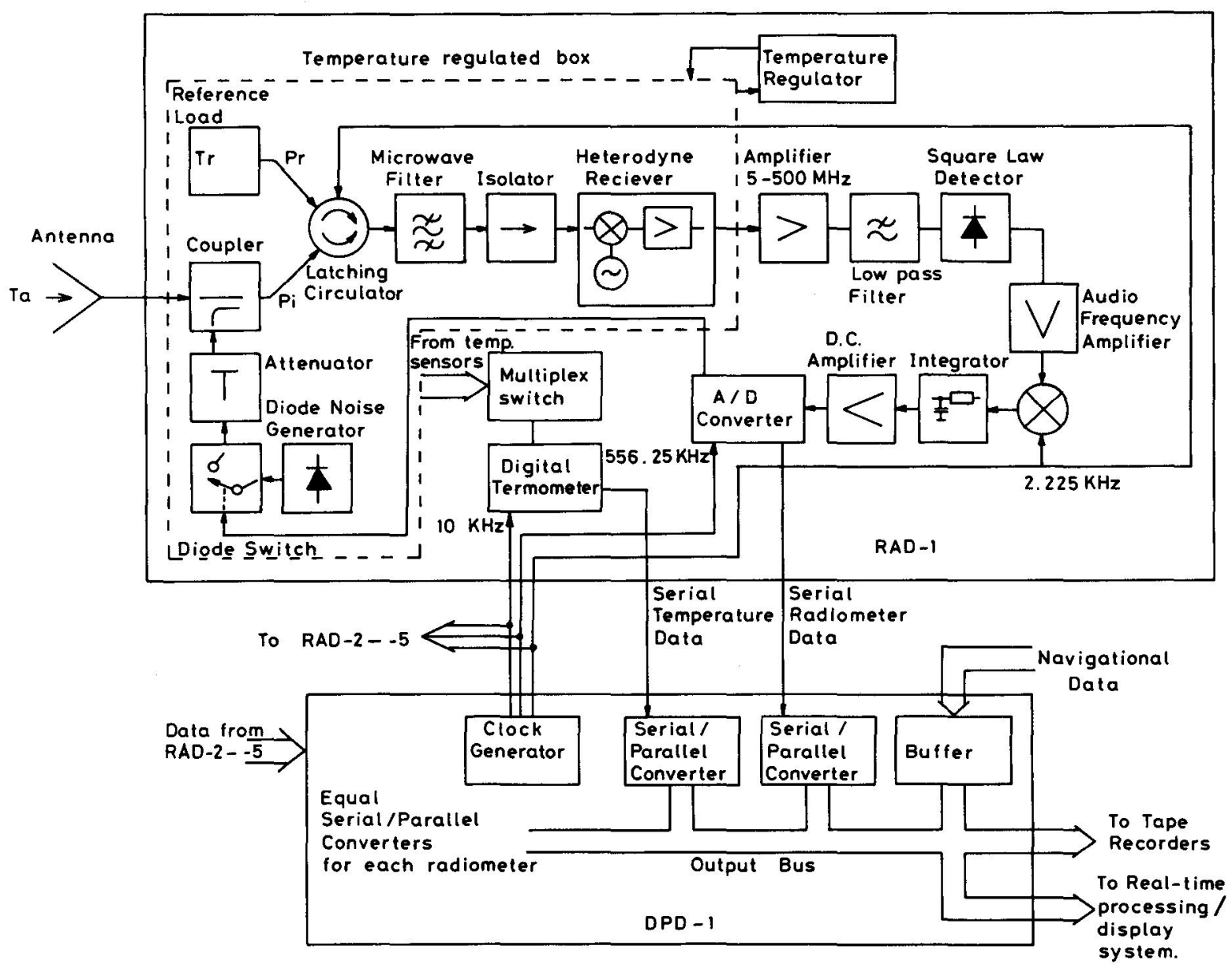

Fig. 1: Block diagram of radiometers.

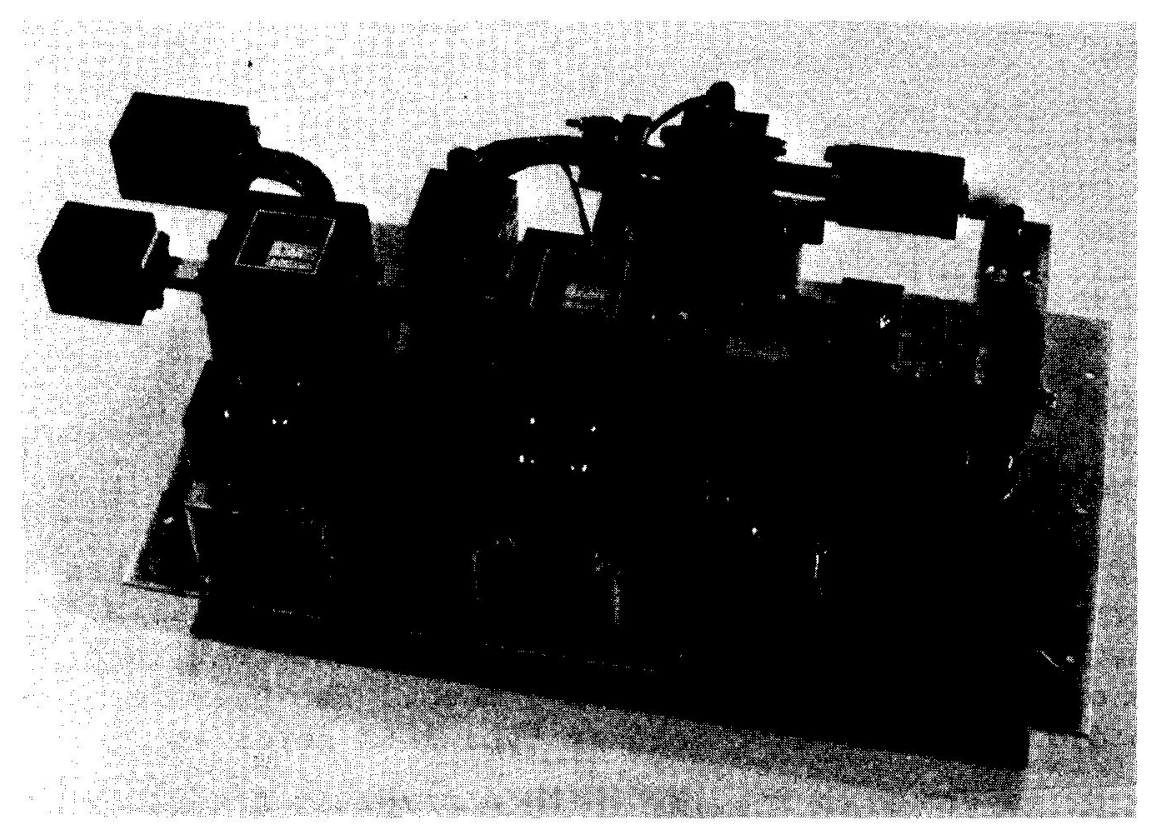

Fig. 2:

The front-end microwave components of the $34 \mathrm{GHz}$ radiometer mounted and ready to go into the temperature stabilized box. Note the two antenna inputs and the multiplex switch which are only found in the $34 \mathrm{GHz}$ radiometer, and not shown in Fig. 1. 
The radiometers mainly being of conventional and well known design, only a few selected topics shall be further commented upon. As mentioned earlier the dwell time per foot print may be as short as $15 \mathrm{~m} \mathrm{sec}$. To ensure a proper sampling of the antenna signal, the radiometers are designed for an integration time of $5 \mathrm{msec}$, determined by the RC-"integrator".

The noise figures of the radiometers being $5.0 \mathrm{~dB}(4.2 \mathrm{~dB}$ for the $5 \mathrm{GHz}$ radiometer) the calculated sensitivities, using the usual formula

$\sigma_{\mathrm{T}}=2 \cdot \frac{\mathrm{T}_{\mathrm{A}}+\mathrm{T}_{\mathrm{N}}}{\sqrt{\mathrm{B} \cdot \tau}}$ are $1.2^{\circ} \mathrm{K}$ (integration time $5 \mathrm{msec}$ ), corresponding to a radiometer constant of $0.085^{\circ} \mathrm{K}$ ( 1 sec integration time).

The temperature range of the radiometers is $0^{\circ} \mathrm{K}-313^{\circ} \mathrm{K}\left(\sim 40^{\circ} \mathrm{C}\right)$ corresponding to maximum injected noise (duty cycle 100\%) and no injected noise (duty cycle 0 ) respectively.

The radiometers are servo systems and the dominant factor in the open loop transfer function $(\mathrm{H}(\mathrm{s})$ ) results from the RC-integrator. Thus:

$$
\mathrm{H}(\mathrm{s}) \sim \frac{\mathrm{H}_{\mathrm{O}}}{1+\mathrm{sRC}}
$$

If an error signal of $0.5^{\circ} \mathrm{K}$ in the servo loop is accepted, $\mathrm{H}_{0}$ is easily calculated:

$$
\mathrm{H}_{\mathrm{O}}=\frac{313}{0.5}=626
$$

The closed loop frequency characteristic is a "RC" $20 \mathrm{~dB}$ per decade rol1-off starting at $63.7 \mathrm{~Hz}$ (corresponding to $5 \mathrm{msec}$ equivalent integration time: $f_{O}=\frac{1}{2 \pi R C}=\frac{1}{\pi \tau}$ ). Hence, the open loop cross-over frequency will
have to be:

and

$$
\mathrm{f}_{\mathrm{RC}}=\frac{63.7 \mathrm{~Hz}}{626}=0.102 \mathrm{~Hz}
$$

$$
\mathrm{RC}=\frac{1}{2 \pi 0.102 \mathrm{~Hz}}=1.56 \mathrm{sec}
$$

which gives

$$
H(s) \sim \frac{626}{1+s 1.56}
$$

No stability problems will arise when closing the feed-back loop, since all other circuit blocks of the radiometer have bandwidths far beyond $63.7 \mathrm{~Hz}$, which is the point of $0 \mathrm{~dB}$ gain for the closed loop.

The pulses from the A/D converter ("voltage to pulse-rate" converter) are counted in $5 \mathrm{msec}$ intervals. Hence, this circuit acts like a digital integrator of the "integrate - and - dump" type, where the integration time is $5 \mathrm{msec}$ and the output is sampled once per $5 \mathrm{msec}$. The transfer function $\left(\mathrm{H}_{I}(f)\right.$ of the digital integrator (sinx/x type with zeros at $\mathrm{n} \cdot \frac{1}{5 \mathrm{~ms}}=\mathrm{n} \cdot 200 \mathrm{~Hz}, \mathrm{n} \neq 0$ ) is shown in Fig. 3. With a sampling frequency of $200 \mathrm{~Hz} 100 \%$ aliasing is observed. The antenna signal is, however, 
band limited to much less than $200 \mathrm{~Hz}$. Firstly the analog integrator suppresses the signal somewhat above $63.7 \mathrm{~Hz}\left(\mathrm{H}_{\mathrm{RC}}(\mathrm{f})\right.$ in $\mathrm{Fig}$. 3), but most importantly the antenna reduces the bandwidth. The response of the antenna, regarding the $34 \mathrm{GHz}$ channel which represents the worst case (highest resolution), is in the time domain:

$$
h_{A}(t)=\left\{\begin{array}{ll}
c & |t| \leq 7.5 \mathrm{msec} \\
0 & |t|>7.5 \mathrm{msec}
\end{array} \quad C\right. \text { is a constant }
$$

provided the antenna has equal gain within the field of view and a gain of zero outside. This is of course not the case for the physical antenna, but it will represent a worst case situation. The Fourier-transform of this function, that is the transfer function $\mathrm{H}_{\mathrm{A}}(f)$ of the antenna in the frequency domain, is shown in Fig. $3(\operatorname{sinx} / x$ type with zeros at $\mathrm{n} \cdot \frac{1}{15 \mathrm{msec}}=\mathrm{n} \cdot 66.7 \mathrm{~Hz}, \mathrm{n} \neq 0$ ).

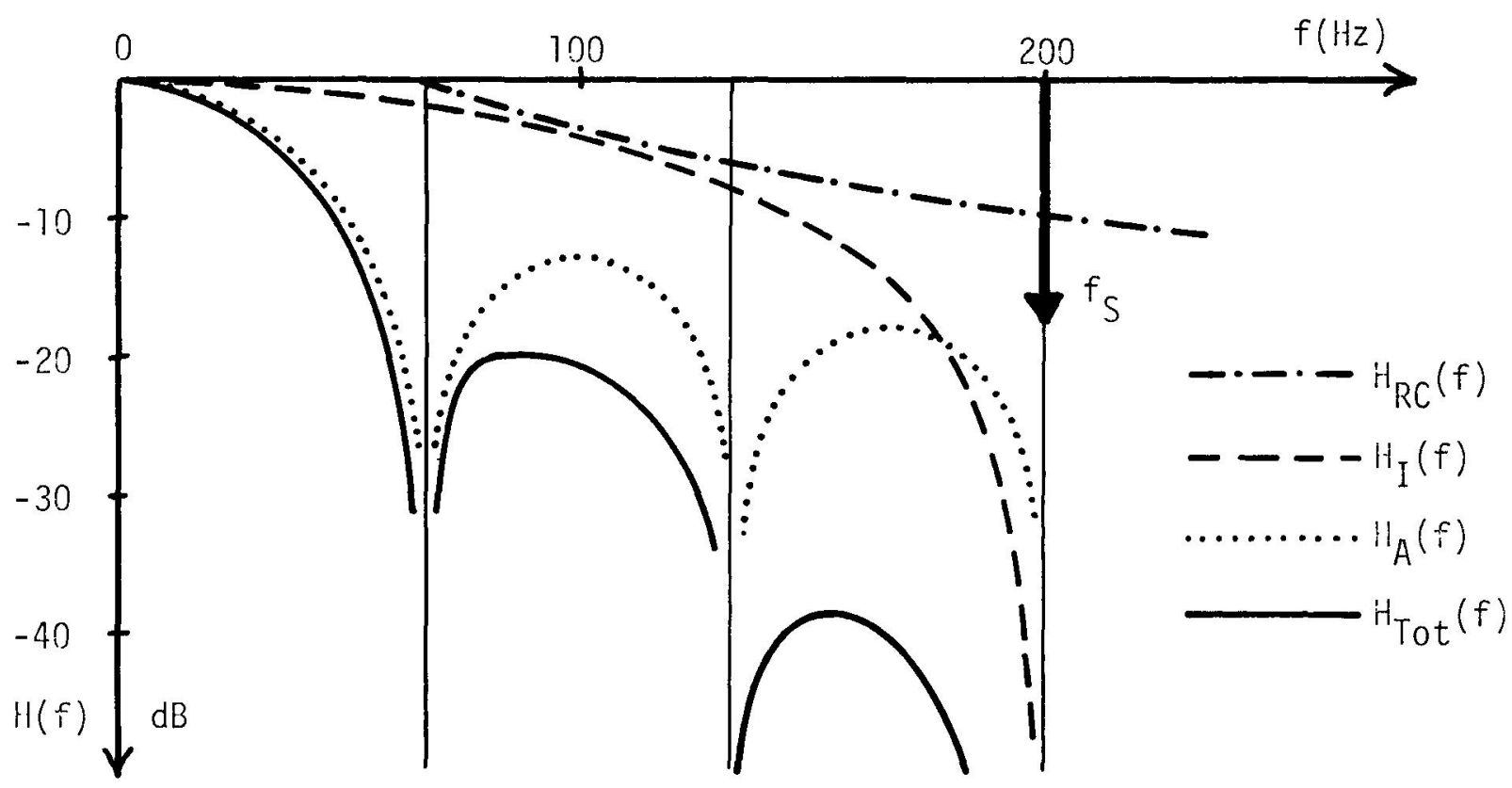

Fig. 3: Transfer functions in the radiometers

The three curves $\left(\mathrm{H}_{\mathrm{RC}}(\mathrm{f}), \mathrm{H}_{\mathrm{I}}(\mathrm{f})\right.$ and $\left.\mathrm{H}_{\mathrm{A}}(\mathrm{f})\right)$ in $\mathrm{Fig} .3$ added together gives the total characteristic of the radiometer in the frequency domain $\left(\mathrm{H}_{\text {tot }}\right.$ (E) in Fig. 3) and it is readily seen that the level of aliasing on the main loop is below some $38 \mathrm{~dB}$ which is quite satisfactory.

References:

[1] Ramseier, Gloersen and Campbell: "Variation in the microwave emissivity of sea ice in the Beaufort and Bering sea", Proc. of URSI meeting on microwave scattering and emission from the Earth, Berne, Sept. 1974.

[2] Hardy et. al: "Development of a satellite microwave radiometer to sense the surface temperature of the world's oceans, NASA CR-1960, Feb. 1972 . 